\title{
Finite Element Simulation of GFRP Reinforced Concrete Beam Externally Strengthened With CFRP Plates
}

\author{
Norhafizah Salleh ${ }^{1,2, *}$, Noor Azlina Abdul Hamid ${ }^{1}$, Abdul Rahman Mohd Sam ${ }^{2}$, Jamalludin \\ Mohd Yatim ${ }^{2}$, Rendy Thamrin ${ }^{3}$, Nur Hafizah A. Khalid ${ }^{2}$, Masni A. Majid ${ }^{1}$, and Zalipah \\ Jamellodin $^{1}$ \\ ${ }^{1}$ Faculty of Civil and Environmental Engineering, Universiti Tun Hussein Onn Malaysia, 86400 Parit \\ Raja, Johor, Malaysia \\ ${ }^{2}$ Faculty of Civil Engineering, Universiti Teknologi Malaysia, 81310 Skudai, Johor, Malaysia \\ ${ }^{3}$ Department of Civil Engineering, Faculty of Engineering, Andalas University, 25163 Sumatera \\ Barat, Indonesia
}

\begin{abstract}
The construction technology now has become more and more advanced allowing the development of new technologies or material to replace the previous one and also solved some of the troubles confronted by construction experts. The Glass Fibre Reinforced Polymer (GFRP) composite is an alternative to replace the current usage of steel as it is rust proof and stronger in terms of stiffness compared to steel. Furthermore, GFRP bars have a high strength-to-weight ratio, making them attractive as reinforcement for concrete structures. However, the tensile behavior of GFRP bars is characterized by a linear elastic stress-strain relationship up to failure and, therefore, concrete elements reinforced with GFRP reinforcement exhibit brittle failure without warning. Design codes encourage over-reinforced GFRP design since it is more progressive and leads to a less catastrophic failure with a higher degree of deformability. Moreover, because of GFRP low modulus of elasticity, GFRP reinforced concrete members exhibit larger deflections and wider cracks width than steel reinforced concrete. This aims of this paper is to developed 2D Finite Element (FE) models that can accurately simulate the respond on an improvement in the deflection of GFRP reinforced concrete beam externally strengthened with CFRP plates on the tension part of beam. The prediction of flexural response according to RCCSA software was also discussed. It was observed that the predicted FE results are given similar result with the experimental measured test data. Base on this good agreement, a parametric study was the performed using the validation FE model to investigate the effect of flexural reinforcement ratio and arrangement of the beams strengthened with different regions of CFRP plates.
\end{abstract}

\footnotetext{
* Corresponding author: nhafizah@uthm.edu.my
} 


\section{Introduction}

Construction industries nowadays face the problem such as durability of the concrete structure due to corrosion. The problem of reinforced steel bar corrosion is one of the most important factors limiting the service life of the structure. Furthermore, repair and retrofit of existing structures are expensive. One of the solutions for this problem is by replacing steel as a reinforcement bar with other material. The suitable alternative material can be used to replace the steel bar is Fiber Reinforced Polymer (FRP). FRP bar can be found with a various type of fiber which is glass, carbon or aramid and they are connected with epoxy resin, polyester or vinyl ester, and therefore be distinguished as GFRP, AFRP, and CFRP products [1]. GFRP is suitable FRP be used to replace the steel due of GFRP give more benefits such as high tensile strength to weight ratio, corrosion free, lightweight, nonmagnetic, and non-conductive than the steel bar [2]. GFRP bars also possess mechanical properties different from steel bars, including high tensile strength combined with low elastic modulus and elastic brittle stress-strain relationship [3]. In comparison with steel, GFRP have higher resistance to corrosion, higher tensile capacity and lower weight.

However, concrete members reinforced with GFRP bars exhibit larger deflection and crack width compare with these reinforced with steel due to low modulus of elasticity. Hence, the structure built with the GFRP bar need to have great support to cover the low of modulus of elasticity. To reduce the deflection and crack using GFRP, the beam is being strengthened with Carbon Fiber Reinforcement Polymer (CFRP) as the external reinforcement. CFRP is another type of high-performance fiber available in civil engineering application. CFRP have more potential service life than aramid and glass fibers. Carbon fiber are manufactured by controlled pyrolysis and crystallization of organic precursors at temperatures above $2000^{\circ} \mathrm{c}$ [4]. This contributes the improvement in reducing the deflection and crack width.

\section{Experimental study}

This study involved a fabrication and testing of 4 reinforced concrete beam with a size, 200 $\mathrm{mm}$ width, $250 \mathrm{~mm}$ depth and $2300 \mathrm{~mm}$ effective length of span and with concrete strength 61.8 MPa. The size beam was selected and design based on the under reinforced (UR) and over reinforced (OR) design and the limitation of testing frame available at the laboratory. The design detail and arrangement of this specimen were shown in Table 1 and Fig. 1. All beams were designed to fail in flexural failure and were test under static load until the beam failed under two point load test.

Table 1. Details of specimens

\begin{tabular}{|c|l|c|c|c|c|l|}
\hline Group & Specimen & av/d & $\begin{array}{c}\text { No of } \\
\text { Tensile } \\
\text { Reinforce }\end{array}$ & $\begin{array}{c}\text { Tensile } \\
\text { Bar Size } \\
\text { (mm) }\end{array}$ & $\begin{array}{c}\text { CFRP } \\
\text { Plate } \\
\text { Length } \\
\text { (mm) }\end{array}$ & note \\
\cline { 4 - 7 } UR & $\begin{array}{l}\text { CG2 } \\
\text { CG2-22 }\end{array}$ & 4.85 & 2 & 13 & - & $\begin{array}{l}\text { Un-Strengthenend } \\
\text { Strengthened }\end{array}$ \\
\hline OR & $\begin{array}{l}\text { CG3 } \\
\text { CG3-22 }\end{array}$ & 4.85 & 3 & 13 & - & $\begin{array}{l}\text { Un-Strengthenend } \\
\text { Strengthened }\end{array}$ \\
\hline
\end{tabular}




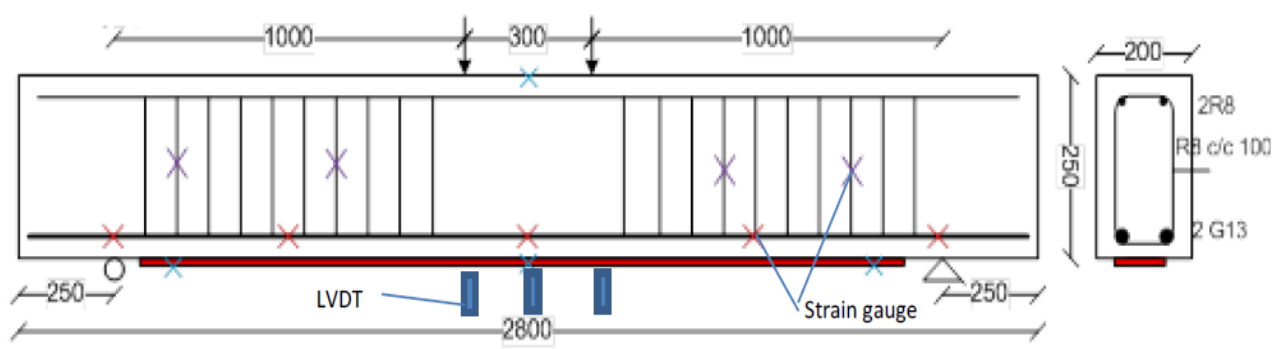

Fig. 1. Arrangement of beam specimen

\section{Finite element (FE) analysis- ATENA}

In this study, a two-dimensional nonlinear finite element analysis was conducted using the finite element package, ATENA. ATENA is a software for analysis of concrete and reinforced concrete structures. ATENA is a fully windows program with integrated prepost-processing and finite element solution. The post-processing and pre-processing are improved significantly. In addition, it contains many new materials, solution methods and other capabilities as for instance options for 2D, plane strain, axisymmetric analysis or shell elements [5]. The numerical predictions are compared to the test results.

\subsection{FE model}

FEA modelled based on measurements made as an experiment before. Fig. 2 shows the parameters for the beam has been in and using the FEA. Note that in this figure only half of the beams' length is represented; in fact, using symmetry, and in order to reduce the computational costs, only half of the beams length was modelled [6].

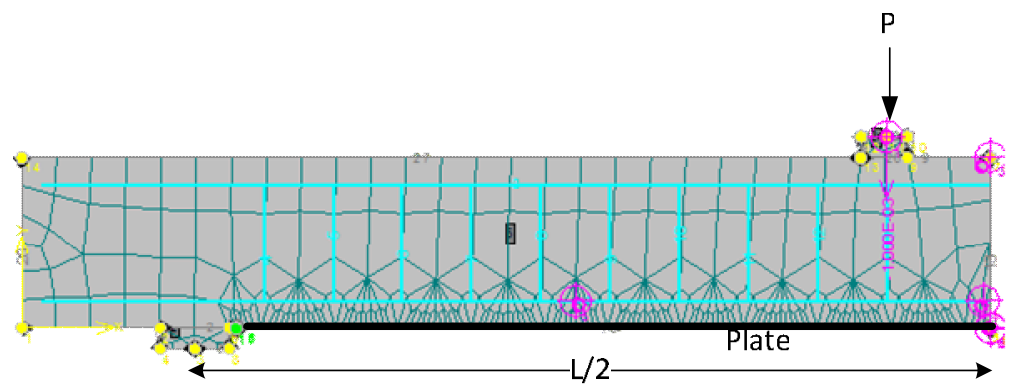

Fig. 2. Geometry of the FE mesh of the beams strengthened with CFRP plate

For descripting the concrete's non-linear behavior, ATENA 2D uses SBETA model, which implements formulations for behaviors as: tension and compression softening, concrete's in tension fracture based on non-linear fracture mechanics, biaxial strength failure criterion, compressive strength reduction after cracking and tension stiffening [5]. SBETA is made by 20 parameters, which can be automatically defined by informing concrete's cubic strength $\left(f_{c u}\right)$. For GFRP's behavior, it's possible to consider as linear modelling. The constitutive models used by ATENA 2D are shown in Fig. 3 and Fig. 4. All properties for element are shown in Table 2. 


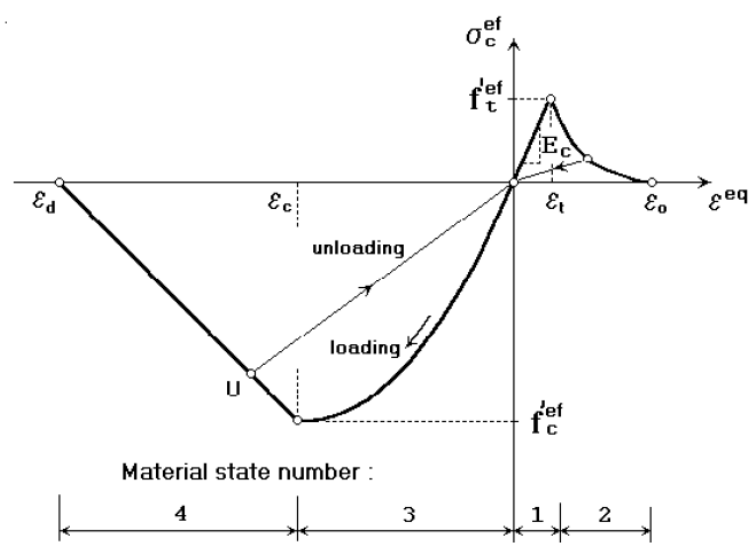

Fig. 3. Uniaxial stress-strain law for concrete [5]

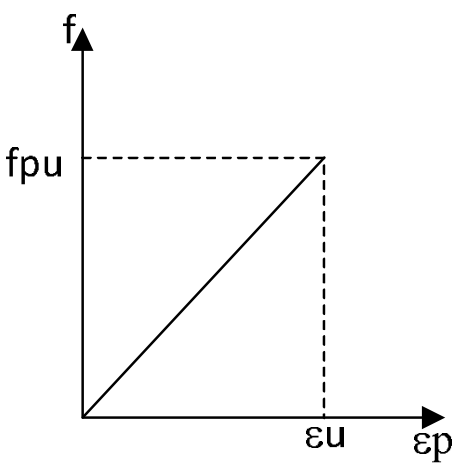

Fig. 4. The linear stress-strain law for GFRP reinforcement

Table 2. Properties of GFRP bar and CFRP plate

\begin{tabular}{|l|c|c|}
\hline \multicolumn{1}{|c|}{ Type of Materials } & GFRP & CFRP \\
\hline Nominal size $(\mathrm{mm})$ & 13 & $100 \times 1.2$ \\
\hline Cross section area $\left(\mathrm{mm}^{2}\right)$ & 201 & 120 \\
\hline Tensile strength $(\mathrm{MPa})$ & 981 & 3100 \\
\hline Elastic modulus $(\mathrm{GPa})$ & 43.6 & 165 \\
\hline Ultimate Elongation $(\%)$ & 2.29 & 1.70 \\
\hline
\end{tabular}

\section{Numerical model using cross sectional analysis (RCCSA Software)}

Numerical model using cross sectional analysis was also carried out. The layered element procedure was used to obtain full flexural response of reinforced concrete cross section. This procedure was implemented into a computer program called Reinforced Concrete Cross Section Analysis (RCCSA) developed by Thamrin [7]. This software also has an ability to predict flexural response of strengthened reinforced concrete cross section. 


\section{Results and discussion}

The load-deflection relationship of experimental, un-strengthened and strengthened beams obtained from the finite element analysis are validated against the experimental results and illustrated in Fig. 5. Comparison of load-deflection curve from the ATENA, RCCSA and experimental shows the same trend of load deflection curves. RCCSA analysis predicts the beam to be stiffer and stronger than ATENA prediction. This is because of the RCCSA using a cross-sectional analytical solution proposed only two kinds of failure, crushing concrete or FRP rupture, can be predicted. Forwarded analysis calculations until crushing concrete or FRP rupture failure modes; thus it appears that the analysis of the cross section (RCCSA) of the beam deflection provides much greater than in experiment and ATENA.

Graph in Fig. 5 shows the increase in load and reduction in deflection occurs for UR beam and beam OR that has been strengthened with CFRP plate. UR beam (CG2-22) load increase of approximately $50 \%$, with a reduction rate of deflection by $40 \%$ which makes the stronger beam. Similarly, look at the beam OR where an increase of load rate of $63 \%$, and $33.3 \%$ reduction for deflection of the beam (CG3-22). This is shown with the addition of CFRP plate at the tension face of beam can increase the strength and stiffness of GFRP RC beam as in [8] previous research.

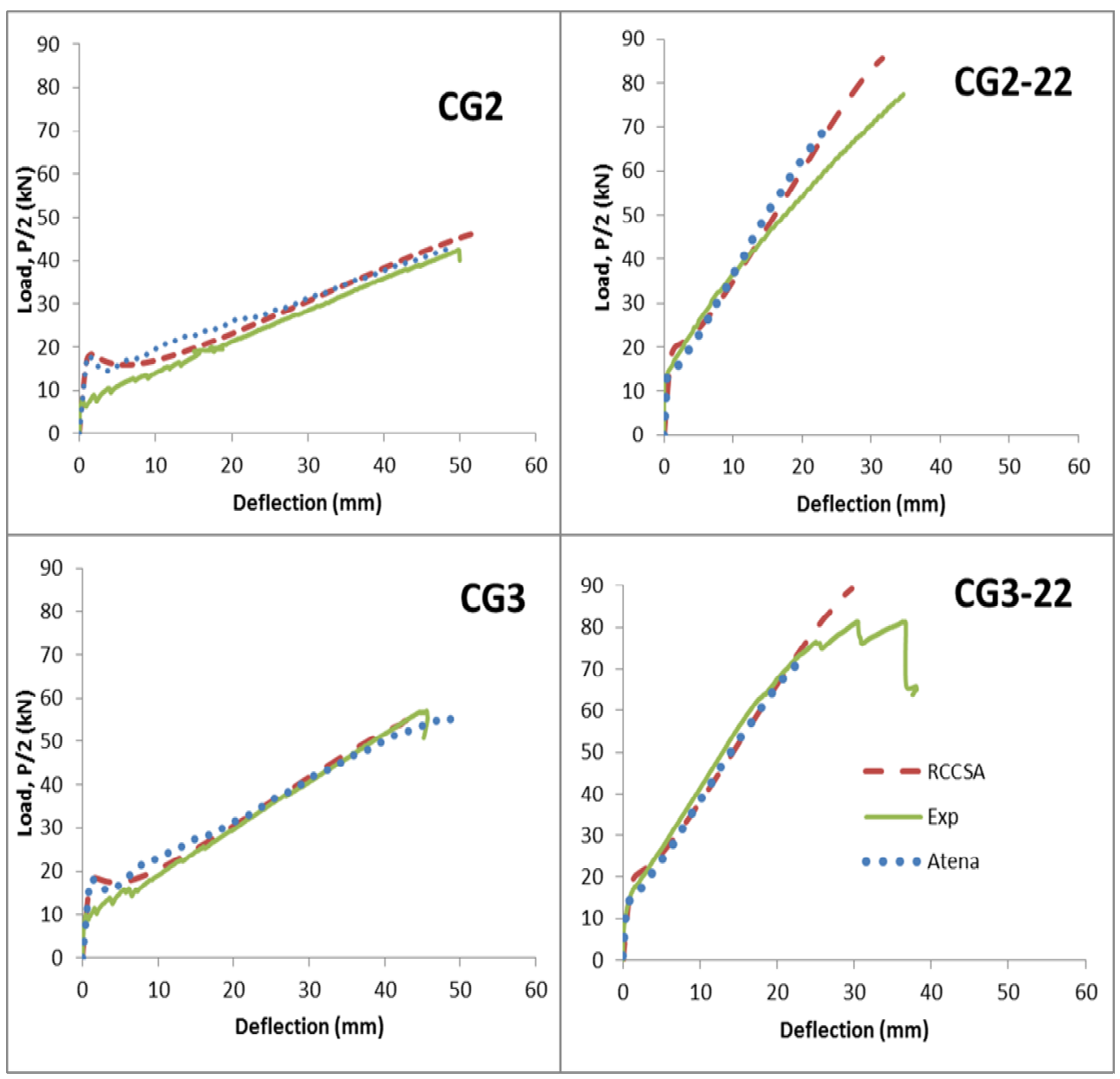

Fig. 5. Load-deflection of beam specimens 


\section{Conclusion}

The general behaviour for FEA capital and RCCSA analysis be shown good agreement with experimental data comparison. The following are the findings that can be produced from studies done:

i) The addition of CFRP on the tension of the beam could fix the maximum value load and maximum deflection that occurs on the beam.

ii) FEA using ATENA can make a simulation for a beam in strengthening with CFRP plate. Expectations for the maximum load of the beam can be obtained correctly.

iii) RCCSA can also produce similar findings with the experimental. Making it easier for the expected results of the experiment will be carried out.

iv) Parametric studies can be made using RCCSA and ATENA, to provide the expected initial findings which will be carried out.

\section{References}

[1] I.F. Kara, A.F. Ashour and C. Dundar, Deflection of concrete structures reinforced with FRP bars, Compos. Part B Eng., 44(1), 375-384 (2013)

[2] A. Rahman, M. Sam and R.N. Swamy, Flexural behaviour of concrete beams reinforced with glass fibre reinforced polymer bars, J. Kejuruteraan Awam, 17(1), 4957 (2005)

[3] Ț. Nicolae, O. Gabriel, I. Dorina and E. Ioana, Fibre reinforced polymer composites as internal and external reinforcements for building elements, Bul. Institutului Politeh. din lasi. Sect. Constr. Arhit., 54(1), 7 (2008)

[4] L. Van Den Einde, L. Zhao and F. Seible, Use of FRP composites in civil structural applications, Constr. Build. Mater., 17(6), 389-403, (2003)

[5] V. Červenka, L. Jendele and J. Červenka, ATENA program documentation part 1 theory, Červenka Consulting, 1-282 (2012)

[6] J.P. Firmo, M.R.T. Arruda, J.R. Correia and C. Tiago, Flexural behaviour of partially bonded carbon fibre reinforced polymers strengthened concrete beams: Application to fire protection systems design, Mater. Des., 65, 1064-1074 (2015)

[7] R. Thamrin and T. Kaku, Development length evaluation of reinforced concrete beam with CFRP bars, Proc. of the Int. Sysmposium on Bond behaviour of FRP in Structure, 385-392 (2005)

[8] N. Salleh, A.R. Mohd Sam, J. Mohd Yatim and M.F. Osman, Flexural behaviour of reinforced concrete beam with glass fiber reinforced polymer (GFRP) bar strengthened with carbon fiber reinforced polymer (CFRP) plate, Adv. Mater. Res., 1051, 748-751 (2014) 